\title{
Therapeutic Allogeneic Lymphocytes
}

National Cancer Institute

\section{Source}

National Cancer Institute. Therapeutic Allogeneic Lymphocytes. NCI Thesaurus. Code C28676.

A population of lymphocytes therapeutically administered to a recipient individual who is genetically distinct from a donor of the same species. ( $\mathrm{NCl04)}$ 